\title{
Improving Female Student Retention in Computer Science during the First Programming Course
}

\author{
Hacer Varol and Cihan Varol
}

\begin{abstract}
This paper is an evaluation study to improve female student retention in Computer Science during the first programming course. Although, colleges are using variety of ways to attract female students to continue their studies in Computer Science, the number of female students is decreasing in the major. Therefore, we have employed two survey studies to learn more about the lack of supported items in the major and tried to address most of those issues in the classroom to see the change in student's feeling about Computer Science. Moreover, we support some of our suggestions not only by the survey results, but also students' performance from the course. We observed that lack of communication among students and with faculty, primitive programming editors, and not well prepared course materials are some of the reasons for the decrease in female student retention.
\end{abstract}

Index Terms-Computer science, female students, programming languages, retention.

\section{INTRODUCTION}

One of the main challenges that engineering and other technology or industry related programs are to recruit and then retain female students until they obtain their degrees from the departments. This fact is also true for Computer Science majors as well. According to [1], in the 2010 and 2011 academic year, the female population in the Computer Science was around 11 percent in the USA. Although, this number has been slightly increasing in the last couple of years, it is still well behind the female population ratio between years 2000 and 2006 [1]. Including this low student ratio for female students, research in technology and education has shown that students are giving up the field all together due to the difficulty in understanding the fundamental concepts and syntax of novice-level programmingafter they start their Computer Science degree. The factors related to retain the students generally include student background characteristics, such as gender, race, and previous education experience; department and institutional characteristics; student-faculty and student peer interaction; student's satisfaction about the program, etc. Therefore, in order to attract more students and increase the retention, different strategies have been used [2], [3]. Some departments offered scholarships [3], companies provided paid internship opportunities and summer trainings [3], and faculty promoted their departments with teaching in different styles and exposing the students with exciting research projects [4]-[7].

Including the listed reasons to change the course of study,

Manuscript received August 14, 2013; revised December 16, 2013.

The authors are with Sam Houston State University, Huntsville, TX77341 USA (e-mail: hxv002@shsu.edu,cvarol@shsu.edu). the first programming language course also has a high impact on the retention of the female students [8]. The main rationale behind this is that some students change their majors after taking the first course from computer science [9].

In this study, we have conducted two surveys with female students who were taking the Programming Fundamentals course at Sam Houston State University. Not only we obtained their main concerns on the course and writing programs, but also we identify a number of things that can be employed in the programming class to improve the female student retention in the Computer Science departments.

The paper is organized as following. In Section II, recent research studies on the increase of student retention in STEM (Science, Technology, Engineering and Mathematics) and in Computer Science field is provided. Section III provides information about the student body at Computer Science Department at Sam Houston State University and the details about the conducted surveys on the female students. The results of the surveys are discussed in Section IV. At the end, the paper is finalized with a Discussion and Conclusion section.

\section{BACKGROUND}

Bowling et al. addressed the rising risk of sophomores and juniors leaving STEM degree with an early undergraduate research program [10]. Students were paid to work part time at a maximum of twenty hours per week. According to the authors, the research program provided a positive influence on the retention of the students [10].

In [11], the authors claimed that the poor student performance is often related to the student's incorrect feeling of understanding the materials. Therefore, they created a virtual human called Dr. Chestr which presents users with questions about $\mathrm{C}++$ programming language.

In [12], the authors claimed that the students who do not feel like they are part of a larger academic community are less likely to participate in extracurricular activities and organizations, which will yield to low retention rates. To address this problem, they presented SNAG (Social Networking Games), a suite of mobile and Internet games which aim to facilitate social networking between members of a group.

Another study to improve student recruiting and retention was conducted by MacLean [13]. According to the author, nationwide Computer Science undergraduate programs suffer from a dropout rate approaching two-thirds of incoming students. Although the number of female students entering the "STEM" fields (Science, Technology, Engineering, and Math) is growing, their numbers still lag. 
The author indicated that it is imperative to recruit and retain more female into these fields and support them until graduation. The author suggested decreasing the "computer guru" culture, increasing the visibility of female students in the recruiting, making introductory computer science courses less intimidating, and preparing different teaching methods that make studying computer science as fun instead of a big challenge [13].

Peckham et al. addressed the decrease in female students at Rhode Island Computer Science program with introducing students to research in computer graphics, art, and new media [14]. With employing mentoring practice, pedagogy, and problem-based learning, they were able to increase the retention rates of the underrepresented female students [14].

Powell et al. claims the improvement of retention in Computer Science with Peer Led Team Learning (PLTL) approach [15]. This approach demonstrates that computer science is necessarily a collaborative activity that focuses more on problem solving and algorithmic thinking than on programming. According to the authors, this program increased the enrollment in the computer science major. Moreover, almost half of the students who took the program with the first programming course majored in Computer Science.

In reference [16], the authors found out that pair programming increased the number of students continuing taking the class and pass rates. This also yields to higher quality of programs, more confidentiality in their work, and more enjoyable time when writing codes [16]. Moreover, the authors claimed that the students who paired are more likely to pass the subsequent programming course that required them to work alone [16].

\section{PARTICIPANTS AND SURVEYS}

At Sam Houston State University (SHSU) although roughly $6 / 10$ 's of the students are female, this rate drops to $4 / 10$ in the introductory level programming course. When we look at the degrees awarded, the female ratio drops to $1 / 10$ in computer science.This reducing numbers of female student population at SHSU's computer science program is consistent with national patterns [1].

Two surveys were conducted to female students throughout the semester to the students who were taking Programming Fundamentals course in a number of different sections. Programming Fundamentals is both a core course for Computer Science majored students but also an elective course for Math, Physics, Criminal Justice, and Computer Animation majored students. Therefore, female students who completed the surveys were from a variety of different majors. As shown in Fig. 1, only about 20 percent of the female population was declared their major as Computer Science.

Since, almost all of the students were holding a high school degree from the state of Texas, some of them had the opportunity to take Java programming course prior to entering to the college. Other than the education gathered from the school, because of their interest, some of them also had programming skills while started to take the Programming Fundamentals course. As reflected from Fig. 2, only about 8 percent of female participants had some programming experience.

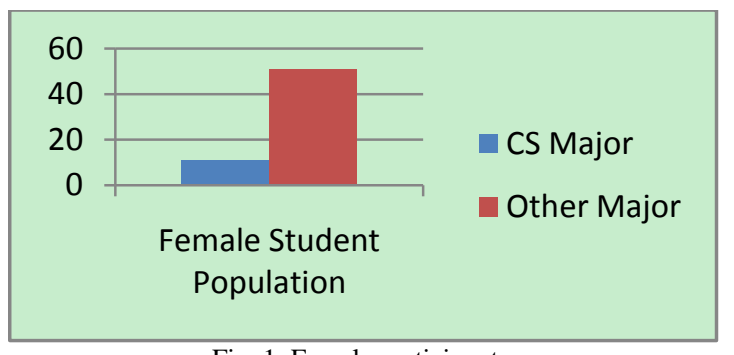

Fig. 1. Female participants.

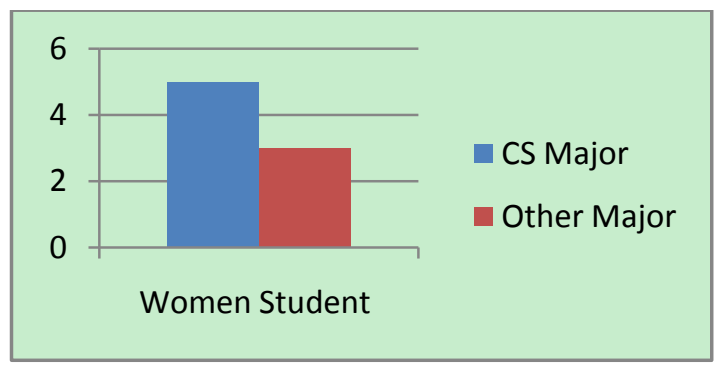

Fig. 2. Prior programming experience.

In this study, specifically, first a preliminary survey was taken in the first quarter of the semester, and another was taken closer to the end of the semester. We were able to obtain feedback from the same set of students in both of the surveys. In the first survey, the questions were focused on students' major, background, computer skills, the time spent on syntax problems vs. logical problems, programming environment used for the course, assignments and labs, their feelings on the teaching assistant support, collaborative work, workload, student activities, and student-faculty interaction. Then we administered a post test survey to see how their feelings have changed throughout the semester. Specifically, in the second survey, the questions were more focused on their feelings on their interest level in computer science.Adding the exam results as the student learning outcomes, our observations are detailed in the following section.

\section{OBSERVATIONS}

\section{A. Challenges with Programming and Proposed Solution}

After the first couple of weeks in the course, the female students indicated their major issues with writing programming. According to the results as shown in Fig. 3, 68 percent of the female students claimed that they were challenged and frustrated with syntax problems and 42 percent also indicated they were having difficulty when creating the algorithm to solve the tasks. Also, it is important to note that since the female students who had priorprogramming experience were not challenged by that time with the concepts, their indications were omitted. Recently we created a Dragon Drop application which addresses the syntax issue and decrease the time spend in debugging with a drag-and-drop feature to improve students' ability to programming while allowing them to grasp main concepts [8]. The editor is designed to generate automatic statements and related syntax according to the programmer's need while minimizing the time spent on fixing the errors 
After the tool was demonstrated, in the second survey, only 9 percent of the students indicated that syntax problems would be an initial issue if the Dragon Drop application was used in the beginning of the class. Moreover, the logical problems as an initial issue also dropped to 29 percent because of the step by step guideline by this application.

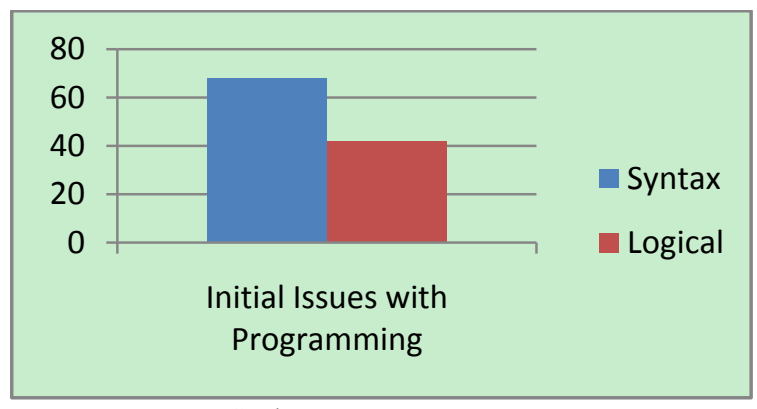

Fig. 3. Female Students' initial issues with programming.

\section{B. Assignments and Labs}

It is a known fact that well prepared related teaching materials are directly associated with retention [17]. In the final survey, students responded about their interest in the assignments and laboratory works and also provided feedback about those. All of the female participants find the materials related to the coursework. 89 percent of the students positively think about the detailed explanation and guideline given with the labs. On the other hand, 64 percent of them suggested having similar structure and partial codes supplied with the assignments as well.

\section{Collaborative Learning}

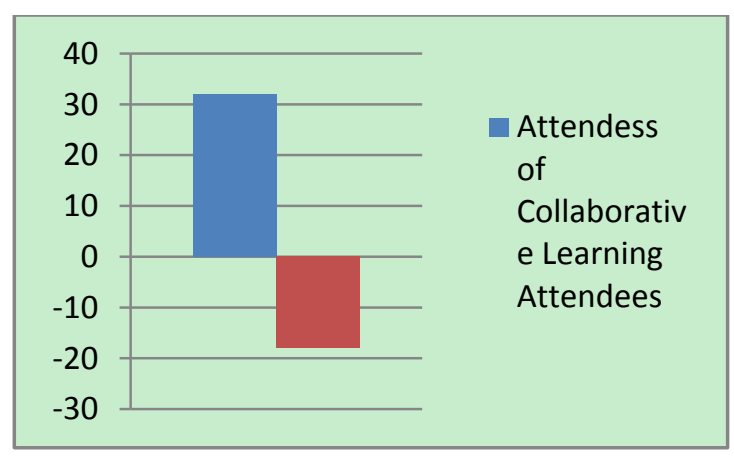

Fig. 4. Collaborative learning outcomes.

Throughout the course, students were assigned to complete the tasks individually. Research in collaborative learning already indicated the improvement in self-assessment of progress, learning, and greater retention in the major. Therefore, they were encouraged to work as a group for discussing course materials or creating pseudo code type algorithms in the study sessions conducted after class hours with proctoring of the faculty or the lab instructor (TA). We observed that these study sessions were often conducted by female students working on assignments and exams. We also measured the outcomes of this collaborative learning in the assignments and in the exam grades as well. The average grade for the collaboratively conducted assignments was 92 compared to 83 for the individual study. Probably the most meaningful result was obtained by the exam results. The female students who attended at least 2 or more study sessions after the first exam increased their score with an average of 32 percent, while this number decreased about 18 percent for other female students as shown in Fig. 4.

\section{Teaching Assistant Role}

A teaching assistant (TA) was assigned to help with the students during the lab hours. Including instructor's office hours, the TA was responsible to hold regular office hours and exam study sessions as well. According to the final survey, 77 percent of the female students indicated that the extra help that they got from the TA, during the office and extra study hours, helped them to easily translate the concepts they learned from the lecture hours to coding.

\section{E. Student-Instructor Interaction}

The interaction between the student and course instructor is considered another important factor for student retention. When students, especially underperforming ones, are asked to join extra study or help sessions by the instructor, they started to feel comfortable talking with the professors and less likely to switch to another major. The survey indicated that 96 percent of the female students were satisfied with the extra help they obtained from the course instructor and TA, which will eventually result in high retention rates.

\section{F. Workload and Prior Programming Experience}

As it can be expected, experienced students performed well compared to the new learners. Therefore, retention of the experienced students is higher than the students who had to put good amount of time for studying the course material. Moreover, heavy workload usually leads to unlikely pursue of Computer Science degree during freshmen or sophomore years based on the 66 percent of the student's response to the survey.

\section{G. Computer Science Student Association}

Not only the faculty-student interaction, but also the interaction among students is also another important factor in retention. If the students feel like they belong to an intellectual and social community while it gives them an opportunity to learn from and create new networks, retention is expected to be increased. One of the students' main complaints from the first survey was the lack of this environment. However, since they were new to the department, instructors later introduced SHACS, Sam Houston Association of Computer Scientists. This association is operated exclusively for educational and scientific purposes:

- To promote an increased knowledge of the science, design, development, construction, language, and applications of modern computing machinery;

- To promote a greater interest in computing machinery and its applications; and

- To provide a means of communication between persons having interest in computing machinery.

After the students were exposed to this knowledge, the second survey clearly indicated student satisfaction in this area.

\section{DisCUSSION AND CONCLUSIONS}

In this paper we tried to point out important issues to 
increase the retention of female students in Computer Science.One of the main issues for the freshmen students are the introductory level programming courses. Being exposed to computer programming first time, it is definitely a challenge for the students. Especially, utilizing a basic text editor for the course is not helping them when constructing the algorithms to solve problems. Therefore, we have introduced a drag-on-drop to the students and received very positive feedback from the students, especially from females. There are short comes of this kind of programming framework, such as not being challenged with debugging process and being find as slow by the experienced programmers. Therefore, the freedom to choose the programming environment needs to be given to the students. With this strategy, experienced students won't feel being ignored. Also if the student opt for the drag-on-drop type framework, the deficiency in the experience of debugging process can be overcame in the upper level programming courses, after the students are familiar with at least one programming language and algorithm structures.Another conclusion we reached was about the lab and assignment materials. Based on the feedback we received from the students, those materials should be prepared in a way so that the students will reminded about the concepts in detail and need to show them some hints or partial codes to solve the problems. These will help struggling students to remember the concepts and build from the pieces to solve the questions.

Such as, acting as a passive role in collaborative learning can be counted as one of the deficiency in this learning style. However, even not being in active role, still the students learn from each other. Therefore, this type of activities needs to be encouraged by the faculty to promote learning and increase retention.

Extra study sessions and an extra hand in labs will positively influence students' involvement in programming. Therefore, the faculty and other personnel, such as TA's, need to allocate extra hours to help students who need help with their tasks. Based on our experience, we found struggling students who do not find extra help are the ones who will drop out the major first.

Student to student interaction should not be limited with the class environment. Asking students to be part of the association that is present in the department will increase the sharing between the students and will create more candid environment for female students. This will eventually yield to higher retention rates.

At the final survey, based on the introduced drag-on-drop application and other addressed issues throughout the course, we evaluated their feelings about Computer Science major in general. Overall, we see $178 \%$ of increase in the feelings of female students about the major. This result provided us that our findings will yield to more comfortable environment for female students in Computer Science, which will result in higher retention rates.

As a future work, we would like to apply our findings starting from the first lecture to the introductory level programming students. At the end of the course, we are planning to evaluate other criterion, such as the female students feeling about if they are thinking that Computer Science is dominated by men and if there are other challenges females are having compared to their men colleagues.

\section{REFERENCES}

[1] S. Zweben. (2012). Computing Degree and Enrollment Trends 2010-2011 CRA Taulbee Survey. Computing Research Association. [Online]. Available: http://www.cra.org/govaffairs/blog/wp-content/uploads/2012/04/CS Degree_and_Enrollment_Trends_2010-11.pdf

[2] J. Roberts and R. Styron, "Student Satisfaction and Persistence: Factors Vital to student retention," Research in Higher Education Journal, vol. 6, pp. 1-18, 2011.

[3] J. M. Cohoon, "Toward improving female retention in the computer science major," Communications of the ACM, 2001.

[4] B. Eugen et al., "Teaching techniques - modern bridges between lecturers and students," presented at 7th WSEAS International Conference on Engineering Education, Corfu Island, Greece July 22-24, 2010, ISBN: 978-960-474-202-8.

[5] D. T. D. Phuong, F. Harada, H. Takada, and H. Shimakawa, "Collaborative Learning Environment with Convincing Opinions for Novice Programmers," presented at 5th WSEAS/IASME International Conference on Engineering Education, Heraklion, Greece, July 22-24, 2008.

[6] J. L. Mauri et al., "Teamwork with University Engineering Students. Group Process Assessment Tool," in Proc. the 3rd WSEAS/IASME International Conference on Educational Technologies, Arcachon, France, October 13-15, 2007, pp. 391-396.

[7] J. A. Betancur, C. Rodríguez, and I. Ezparragoza, "An undergraduatecollaborative design experience among institutions in the Americas," presented at the 8th WSEAS International Conference on Engineering Education, Corfu Island, Greece July 14-16, 2011 , ISBN: 978-1-61804-021-3.

[8] S. Silessi, C. Varol, and H. Varol, "Non-Computer Science Majored Women Students Perspective on a Pictorial Programming Environment," International Journal of Education and Information Technologies, vol. 7, issue 2, May 2013, pp. 44-51, ISSN: 2074-1316.

[9] C. McDowell, L. L. Werner, H. E. Bullock, and J. Fernald, "Pair programming improves student retention, confidence, and program quality," Communications of ACM, vol. 49, no. 8, pp. 90-95, 2006.

[10] B. Bowling, H. Bullen, M. Doyle, and J. Filaseta, "Retention of STEM Majors Using Early Undergraduate Research Experiences," in Proc. the 44th ACM Technical Symposium on Computer Science Education, Denver, USA, March 6-9 2013, pp. 171-176.

[11] C. Arrington, D. M. Wilson, and L. Lehmann, "Improving Performance and Retention in Computer Science Courses Using a Virtual Game Show," in Proc. the $49^{\text {th }}$ Annual Southeast Regional Conference, Kennesaw, GA, March 24-26 2011, pp. 320-321.

[12] S. L. Finkelstein, E. Powell, A. Hicks, K. Doran, S. R. Charugulla, and T. Barnes, "SNAG: Using Social Networking Games to Increase Student Retention in Computer Science," in Proc. the Fifteenth Annual Conference on Innovation and Technology in Computer Science Education, Ankara, Turkey, June 26-30 2010, pp. 142-146.

[13] L. MacLean, "Recruitment and Retention of Women in Computer Science and Information Systems: How and Why," in Proc. 2nd International Conference on Education and New Learning Technologies, Barcelona, Spain, July 5-7 2010, pp. 1585-1591.

[14] J. Peckham, P. D. Stephenson, J. Y. Hervé, R. Hutt, and L. M Encarnação, "Increasing Student Retention in Computer Science Through Research Programs for Undergraduates," in Proc. The 38th SIGCSE Technical Symposium on Computer Science Education, Covington, Kentucky, USA March 7-10 2007, pp. 124-128.

[15] R. M. Powell, C. Murphy, A. Cannon, J. Gordon, and A. Ramachandran, "Emerging Scholars Program- a PLTL-CS Program that Increases Recruitment and Retention of Women in the Major," University of Pennsylvania Department of Computer and Information Science Technical Report No. MS-CIS-12-16, January 2012.

[16] C. McDowell, L. Werner, H. F. Bullock, and J. Fernald, "Pair Programming Improves Student Retention, Confidence, and Program Quality," Communications of the ACM, vol. 49, no. 8, pp. 90-95, 2006.

[17] L. Barker, C. McDowell, and K. Kalahar, "Exploring Factors that Influence Computer Science Introductory Course Students to Persist in the Major," SIGCSE Bulletin, vol. 41, no. 2, 2009, pp. 282-286.

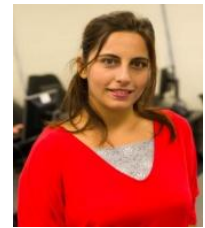

Hacer Varol received her bachelor of science degree in electrical and electronics engineering from Firat University, Elazig, Turkey in 2003, master of science degree from applied science from University of Arkansas at Little Rock, Little Rock, AR, USA in 2011, and currently pursuing doctorate degree in electrical engineering from Lamar University, Beaumont, TX, 
USA.

She has been working as lecturer at the Department Computer Science at Sam Houston State University, since 2011. Her research interests are space network communications, computer science education, educational technology, and biomedical signal processing.

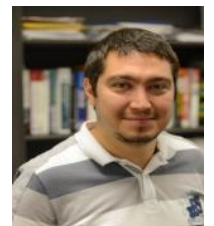

Cihan Varol received his bachelor of science degree in computer science from Firat University, Elazig, Turkey in 2002, master of science degree from Lane Department of Computer Science and Electrical Engineering from West Virginia University, Morgantown, WV, USA in 2005, and doctor of philosophy in applied computing from University of Arkansas at Little Rock, Little Rock,
He has been working as Assistant Professor of Computer Science at Sam Houston State University, since 2009. His research interests are in the general area of information (data) quality, VoIP Forensics, and risk management with specific emphasis on personal identity recognition, record linkage, entity resolution, pattern matching techniques, natural language processing, multi-platform VoIP applications, VoIP artifacts data cleansing, and quality of service in business process automation.

Dr. Varol is an executive committee member of International Symposium on Digital Forensics and Security. Dr. Varol has served as keynote speaker and session chair in multiple conferences. Dr. Varol is an editor of three journals and has been reviewing papers for a number of ACM and IEEE journals. Dr. Varol published more than 30 peer-reviewed journal and conference publications, and one book chapter. 